\title{
Removal of a gastric wall lesion with a new technique: direct intragastric hybrid resection
}

We performed an upper endoscopy in a 46-year-old woman in an outpatient setting for dyspeptic symptoms. Endoscopy revealed a $25-\mathrm{mm}$ subepithelial lesion in the subcardial area, which was not identified during an endoscopy performed 1 year previously. As endoscopic biopsies were nondiagnostic (normal gastric mucosa), we decided to perform positron emission tomography/computed tomography, which revealed a positive uptake by the lesion.

We decided to remove the lesion; however, as the location was difficult for surgical resection, we consulted with the patient and selected a nonconventional approach ( Video 1$)$ [1, 2].

1. Creation of the abdominal access.

We performed a gastropexy with percutaneous gastrostomy T-tags, and passed two guidewires for parallel access points. Two laparoscopic trocars were introduced over the guidewires and into the stomach to allow for passage of a clamp and stapler [3] ( Fig. 1).

2. Removal of the lesion. Under endoscopic view, the lesion was grasped with the clamp and pulled to allow its capture with the stapler [4]. Endoscopic ultrasound assessed the entire lesion as it was captured, and the endoscopic view revealed that the stapler was not in contact with adjacent gastric walls. The resection was then performed. The lesion was captured with a basket and removed endoscopically. The scar was checked, revealing a complete seal without complications ( $\mathbf{F i g . 2}$ ).

3. Closure of the access. The surgical equipment was removed and the access sites were closed with two full-thickness endoscopic clips [5] ( Fig.3).

4. Final diagnosis and follow-up. Histological analysis confirmed that the resection was complete. It was a smooth muscle tumor, C-KIT nega-

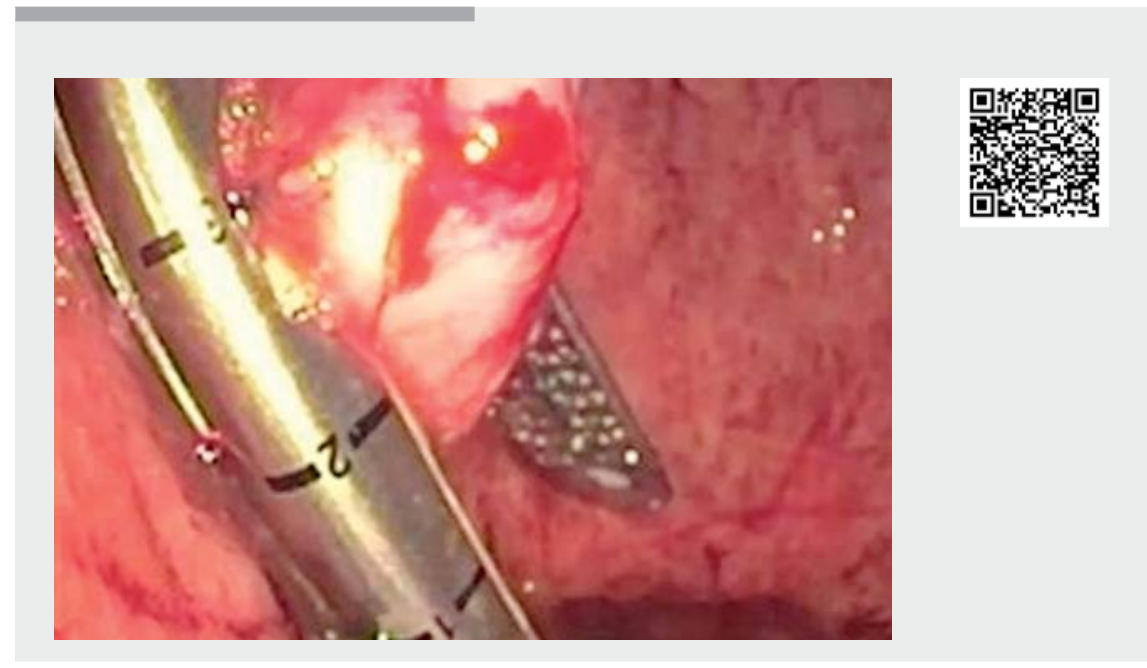

Video 1 Direct intragastric hybrid (endoscopic-laparoscopic) resection.

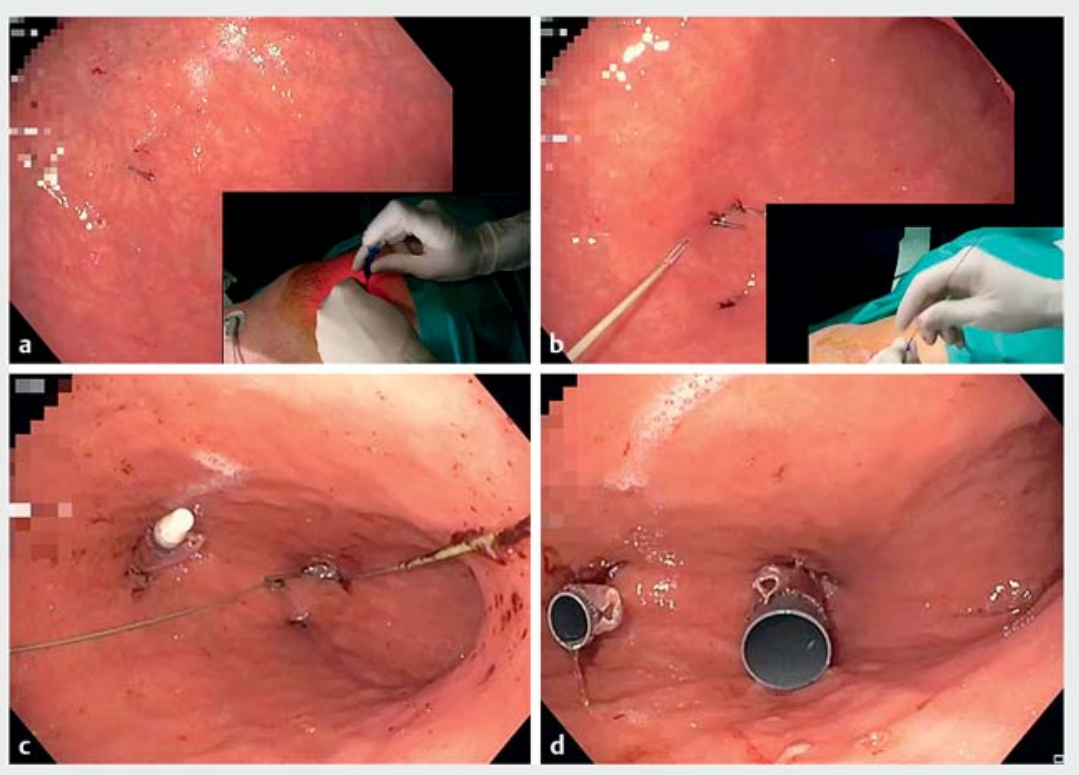

- Fig. 1 Direct transabdominal intragastric access. a Gastropexy with T-tags. b Creation of the access and passage of the guidewires. $\mathbf{c}, \mathbf{d}$ Introduction of the surgical trocars.

tive, and Desmin positive. These findings were consistent with the diagnosis of leiomyoma ( $\triangleright$ Fig.4). At followup 1 year later, the scar was very small and the closure clips remained in situ (> Fig.5).

Endoscopy_UCTN_Code_TTT_1AO_2AN FB 

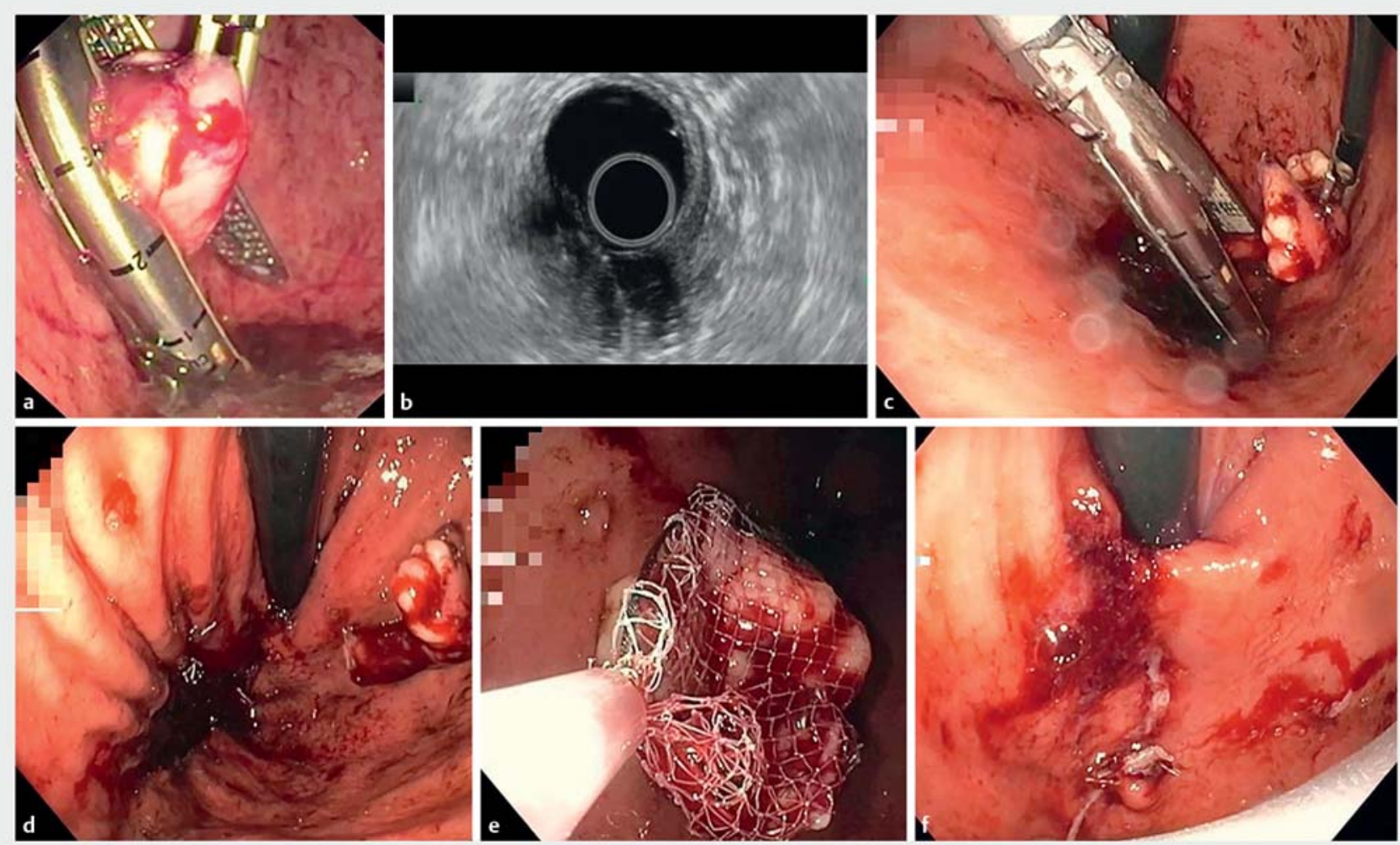

- Fig. 2 Removal of the lesion. a The lesion was grasped with the clamp and captured with the stapler. $\mathbf{b}$ Endoscopic ultrasound exam. The entire lesion was captured. $\mathbf{c}$ Resection with the stapler. $\mathbf{d}$ The resected lesion. $\mathbf{e}$ The lesion was captured with a net. $\mathbf{f}$ View of the scar.
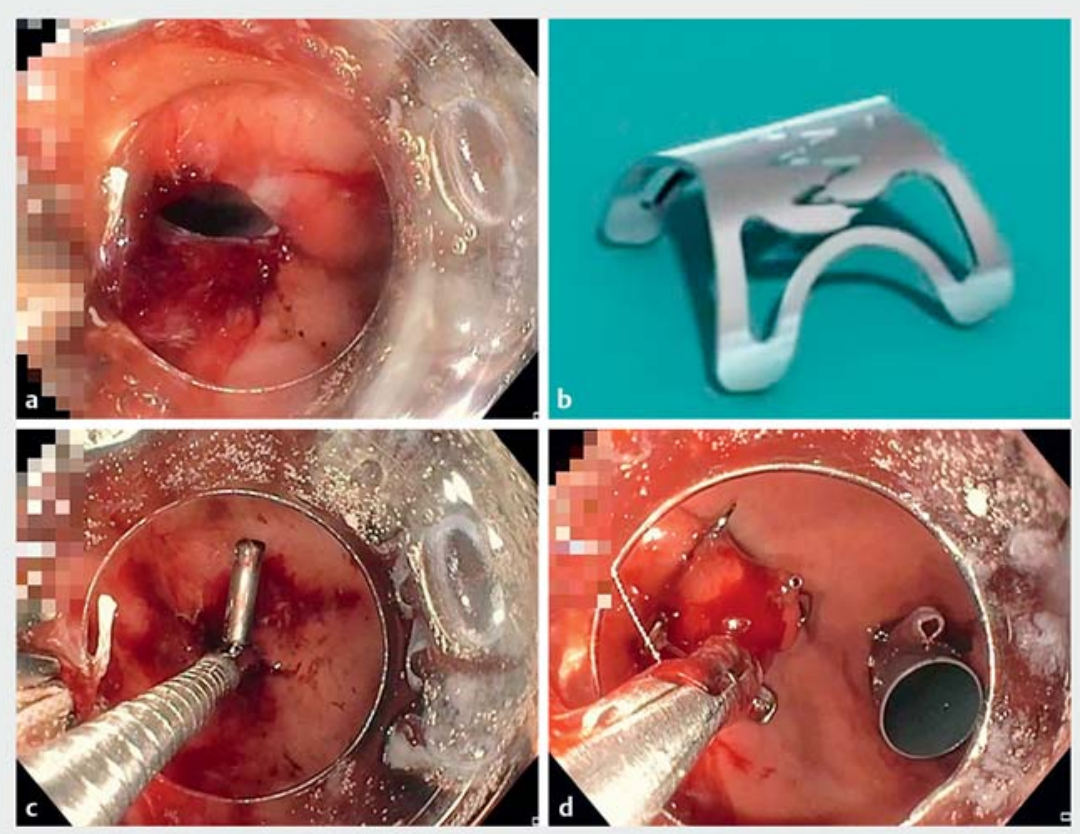

Fig. 3 Closure of the access. a Gastric orifices after the trocars had been removed. b Overthe-scope clip. c, d Closure of the orifices.

\section{Competing interests}

None

The authors

Fernando González-Panizo', David Fernández Luengas ${ }^{2}$, Enrique Vázquez Sequeiros ${ }^{1}$, Jesús Merello Godino ${ }^{2}$, Álvaro Rojas Sánchez ${ }^{1}$, Diego Juzgado Lucas ${ }^{1}$

1 Endoscopy Unit, Gastroenterology Department, University Hospital Quirónsalud Madrid, Spain

2 Department of General and Digestive Surgery, University Hospital Quirónsalud Madrid, Spain

\section{Corresponding author}

\section{Fernando González-Panizo, MD}

Endoscopy Unit, Gastroenterology

Department, University Hospital

Quirónsalud, Diego de Velázquez, 1, 28223,

Pozuelo de Alarcón, Madrid 28223, Spain

Fax: +34-91-4521900

fernandogpanizo@gmail.com 


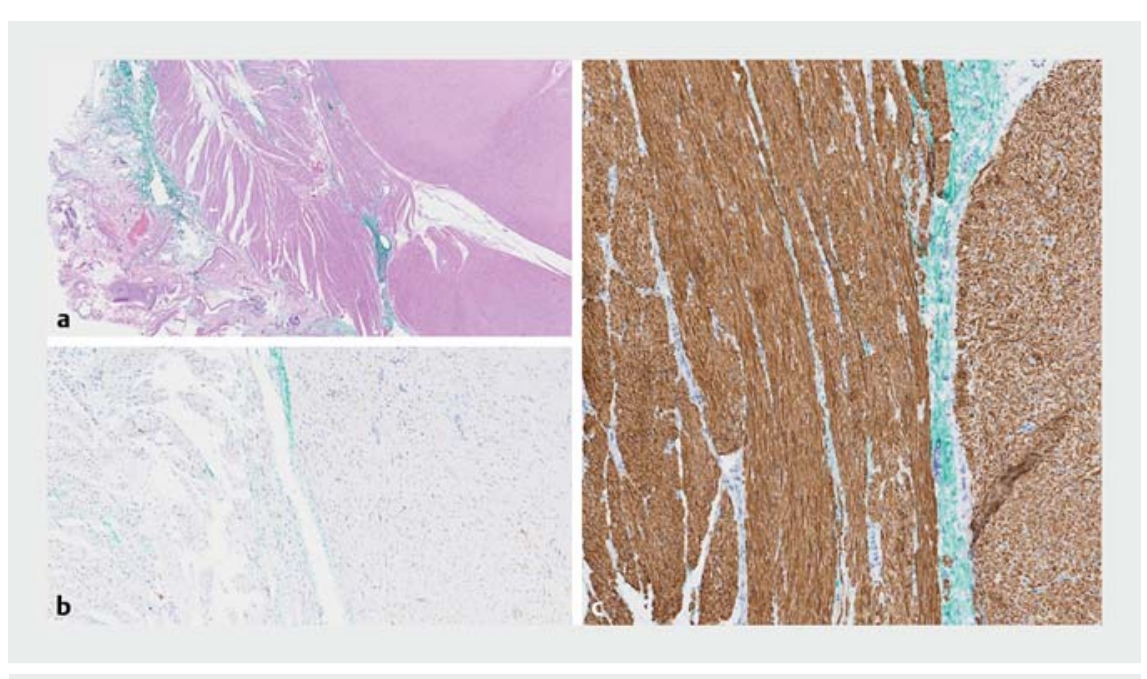

- Fig. 4 Histological analysis. a Tumor and muscle layer. b C-KIT negative. c Desmin positive.

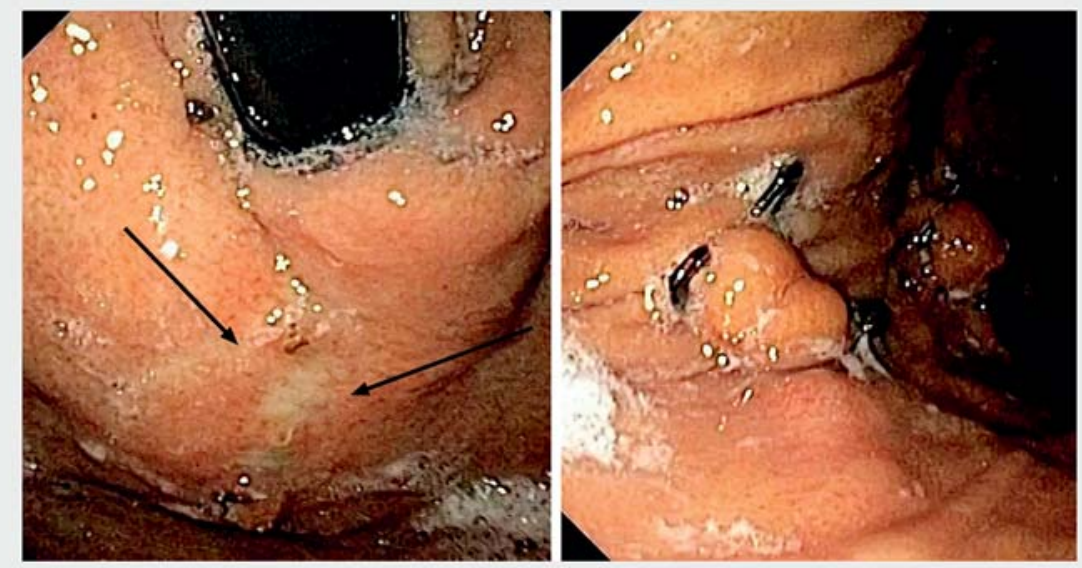

Fig. 5 Follow-up. Scar (arrows) and closure clips in endoscopic view 1 year later.

[1] Aisu Y, Yasukawa D, Kimura Y et al. Laparoscopic and endoscopic cooperative surgery for gastric tumors: perspective for actual practice and oncological benefits. World J Gastrointest Oncol 2018; 10: 381-397

[2] Lim SG, Hur H, Han SU et al. Laparoscopyassisted endoscopic full-thickness resection for gastric subepithelial tumors originated from the muscularis propria layer: a pilot study with literature review. Scand J Gastroenterol 2017; 52: 257-263

[3] Sahm M, Pross M, Lippert H. Intraluminal resection of gastric tumors using intragastric trocar technique. Surg Laparosc Endosc Percutan Tech 2011; 21: e169-e172

[4] Ridwelski K, Pross M, Schubert S et al. Combined endoscopic intragastral resection of a posterior stromal gastric tumor using an original technique. Surg Endosc 2002; 16 : 537

[5] Pross M, Wolff S, Nestler G et al. A technique for endo-organ resection of gastric wall tumors using one intragastric trocar. Endoscopy 2003; 35: 613-615

\section{Bibliography}

DOI https://doi.org/10.1055/a-1027-6173

Published online: 12.2.2020

Endoscopy 2020; 52: E281-E283

(c) Georg Thieme Verlag KG

Stuttgart · New York

ISSN 0013-726X

\section{ENDOSCOPY E-VIDEOS \\ https://eref.thieme.de/e-videos}

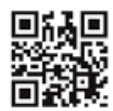

Endoscopy E-Videos is a free access online section, reporting on interesting cases and new

techniques in gastroenterological endoscopy. All papers include a high quality video and all contributions are freely accessible online.

This section has its own submission website at

https://mc.manuscriptcentral.com/e-videos 